\title{
First but not second postoperative day growth hormone assessments as early predictive tests for long-term acromegaly persistence
}

\author{
V. Cambria ${ }^{1}$ (D) G. Beccuti ${ }^{1} \cdot$ N. Prencipe ${ }^{1} \cdot$ F. Penner ${ }^{2} \cdot$ V. Gasco $^{1} \cdot$ F. Gatti ${ }^{1} \cdot$ M. Romanisio ${ }^{1} \cdot$ M. Caputo ${ }^{3} \cdot$ E. Ghigo $^{1}$. \\ F. Zenga ${ }^{3} \cdot$ S. Grottoli ${ }^{1}$
}

Received: 29 November 2020 / Accepted: 10 March 2021 / Published online: 10 April 2021

(c) The Author(s) 2021

\begin{abstract}
Purpose Postoperative assessment of acromegaly activity is typically performed at least 3 months after neurosurgery (NS). Few studies have evaluated the use of early postoperative growth hormone $(\mathrm{GH})$ levels as a test to predict short- and long-term remission of acromegaly. Our objective was to evaluate the diagnostic performance of serum random GH on a postoperative day one (D1-rGH) and two (D2-rGH), particularly in predicting long-term disease persistence.

Materials and methods Forty-one subjects with acromegaly who were undergoing NS were enrolled (mean age \pm SD $47.4 \pm 13.1$ years at diagnosis; women $54 \%$; macroadenomas $71 \%$ ). The final assessment of disease activity was performed one year after NS. ROC curves were used to evaluate the diagnostic performance of D1-rGH and D2-rGH.

Results After a 1-year follow-up, the overall remission rate was 55\%. ROC analysis identified an optimal D1-rGH cut-off value of $2.1 \mathrm{ng} / \mathrm{mL}$ for diagnosing long-term disease persistence $(55.6 \% \mathrm{SE} ; 90.9 \% \mathrm{SP})$. The cut-off point became $2.5 \mathrm{ng} / \mathrm{mL}$ after maximizing specificity for disease persistence (yielding a $100 \%$ positive predictive value) and $0.3 \mathrm{ng} / \mathrm{mL}$ after maximizing sensitivity for disease remission. The optimal D2-rGH cut-off value was $0.6 \mathrm{ng} / \mathrm{mL}(81.8 \% \mathrm{SE}$; $50 \% \mathrm{SP})$; the cut-off point became $2.9 \mathrm{ng} / \mathrm{mL}$ after maximizing specificity and $0.1 \mathrm{ng} / \mathrm{mL}$ after maximizing sensitivity, with no clinical utility.

Conclusions D1-rGH could be a highly specific test for the early diagnosis of long-term acromegaly persistence, which is predicted by a value $>2.5 \mathrm{ng} / \mathrm{mL}$ with a great degree of certainty. The diagnostic performance of D2-rGH was insufficient. Further research is required to validate these preliminary results prior to modifying the postoperative management of acromegaly.
\end{abstract}

Keywords Growth hormone $\cdot$ Acromegaly $\cdot$ Disease persistence $\cdot$ Early prediction

V. Cambria and G. Beccuti contributed equally to this work.

G. Beccuti

guglielmo.beccuti@unito.it

V. Cambria

cambriav7@gmail.com

1 Division of Endocrinology, Diabetes and Metabolism, Department of Medical Sciences, University of Turin, Corso Dogliotti 14, 10126 Turin, Italy

2 Division of Neurosurgery, Department of Neurosciences "Rita Levi Montalcini", University of Turin, Turin, Italy

3 Division of Endocrinology, Department of Translational Medicine, University of Eastern Piedmont "Amedeo Avogadro", Novara, Italy

\section{Introduction}

Neurosurgery (NS) is considered the first choice to cure acromegaly. In the literature, the remission rate is variable (56-72\%) depending on the clinical center and operator [1]. Moreover, the probability of remission is different between micro- (>85\%) and macroadenomas (40-50\%) [2]. Technical progress has improved surgical outcomes to achieve a post-NS remission rate of $60-85 \%$ in the largest cohorts $[3,4]$.

Re-evaluation of the disease state after NS is typically performed by measuring IGF1 and nadir GH after an oral glucose tolerance test (OGTT) at least 12 weeks post-intervention due to the long half-life of IGF1 $[2,5]$.

The American Association of Clinical Endocrinologists (AACE) guidelines for acromegaly recommend that "a fasting GH level be measured early postoperatively" to predict 
long-term remission (recommendation n. 47, "best evidence" level 2, Grade C) [6]. In fact, the short half-life of GH could allow the early prediction of the disease state. Soon after NS, $\mathrm{GH}$ levels decrease as a result of the ischemia and fibrosis of residual adenomatous tissue or adenoma removal; the only source of GH production should be normal somatotropic cells, which are still suppressed by the previously high levels of GH and IGF1 [7].

Postoperative cortisol is a recognized predictor of Cushing disease remission, while in acromegaly, the use of postoperative GH has not yet been fully explored.

Some studies have attempted to assess the prognostic role of early random $\mathrm{GH}$ determination with different cut-off levels and times, as well as other early postoperative biochemical tests (mean GH, IGF1, nadir GH after OGTT); however, many pitfalls must be considered to avoid incorrect decisions. In fact, in comparison with $\mathrm{GH}$, the decline in IGF1 is delayed due to the longer half-life of IGF-binding proteins. Nadir GH after an OGTT may slightly change over time, from immediately postoperatively to 3 months after NS [8]. A prospective study evaluated the predictive role of random GH and IGF1 on a postoperative day one and nadir GH following an OGTT $2-4$ days after NS [9]. The authors showed that early determination of IGF1 was not useful for predicting disease state; however, the proposed cut-offs for random GH and nadir GH appeared to demonstrate good positive predictive values for remission but inadequate specificity [9].

Early random GH could be considered a simple and cheap test that is entirely feasible for the postoperative management of acromegaly; a specific and reproducible cut-off point is needed to discriminate between cured patients and those with a high risk of persistent or recurrent disease.

The present study aimed to evaluate the diagnostic performance of GH determination on postoperative days one and two for the early prediction of acromegaly persistence at 1 year after pituitary surgery.

\section{Materials and methods}

We prospectively recruited 41 consecutive subjects with acromegaly who were undergoing NS for pituitary adenoma at the Division of Neurosurgery of the "City of Health and Science of Turin" University Hospital (Turin, Italy) between 2014 and 2018. All surgical procedures were performed by a single neurosurgeon dedicated to pituitary surgery (FZ), using a 3D endoscopic endonasal approach; only one patient needed a combined transcranial and endonasal approach due to a "supergiant" GH-secreting pituitary adenoma [10].

Serum IGF1 was assessed at diagnosis and three months and one year after NS. Serum random GH $(\mathrm{rGH})$ was assessed on day one, day two, and three months after NS.
Nadir GH after an OGTT (nGH) was measured three months after NS; adequate inhibition of GH after the OGTT was defined as $\mathrm{nGH}<1.0 \mathrm{ng} / \mathrm{ml}$.

Contrast-enhanced magnetic resonance imaging was performed three months after NS.

Acromegaly persistence at the end of the one-year followup was defined as the use of medical therapy or the need for radiation therapy due to disease persistence or recurrence after NS, or an IGF1 value above the age-dependent upper limit of normal (ULN) of the Italian population [11], expressed as both absolute value and IGF1 times ULN $(\mathrm{IGF} 1 \times \mathrm{ULN})$; on the contrary, disease remission was defined by an IGF1 value below the age-dependent ULN of the Italian population, without active medical therapy or exposure to radiation therapy.

Serum GH levels (ng/mL) were measured using an immunoradiometric assay (IRMA GH, Beckman Coulter, Czech Republic), and serum IGF1 levels ( $\mathrm{ng} / \mathrm{mL}$ ) were measured by a radioimmunoassay technique (SM-C-RIA-CT, DIAsource ImmunoAssays, Belgium) following acid-ethanol extraction to avoid interference of binding proteins.

Data are presented as the mean \pm standard deviation (SD), or the median (interquartile range) for skewed variables. Statistical analysis was performed using the Stata program (version 14; Stata Corporation, College Station, TX, USA). The Mann - Whitney $U$ test was employed for continuous variables, whose non-normal distribution was attributed to the limited sample size, and the chi-square test was used for categorical variables.

Receiver Operating Characteristics (ROC) analysis was carried out to identify the D1- and D2-rGH cut-off values with the optimal sensitivity/specificity pairing, the highest specificity for acromegaly persistence, and the highest sensitivity for disease remission.

\section{Results}

The demographic and clinical characteristics of the participants are summarized in Table 1. Of the 41 subjects, 54\% were women. The mean age was $47.4 \pm 13.1$ years at diagnosis and $49.0 \pm 12.5$ years at NS. All patients were affected by a GH-secreting pituitary adenoma ( $71 \%$ macroadenomas) with a median diameter of $12 \mathrm{~mm}(8-21)$.

At diagnosis, the median IGF1 was $848 \mathrm{ng} / \mathrm{mL}$ (546-1105) and the median IGF1 (x ULN) was 2.9 $(1.9-3.7)$. Neoadjuvant therapy with a somatostatin analog was given to $42 \%$ of patients and discontinued at least 3 months prior to NS to avoid pharmacological interference in subsequent biochemical assessments.

Three months after NS, a residual adenoma was found in $34 \%$ of patients by contrast-enhanced magnetic resonance imaging. Among these, $71 \%$ had originally been affected by 
Table 1 Demographic and clinical features of the study population

\begin{tabular}{ll}
\hline Characteristics & All subjects $(n=41)$ \\
\hline Gender & \\
Women, $n(\%)$ & $22(54)$ \\
Men, $n(\%)$ & $19(46)$ \\
Age, years & $47.4 \pm 13.1$ \\
Neoadjuvant therapy, $n(\%)$ & $17(42)$ \\
Adenoma diameter, mm & $12(8-21)$ \\
Microadenoma, $n(\%)$ & $12(29)$ \\
Macroadenoma, $n(\%)$ & $29(71)$ \\
Residual, $n(\%)$ & $14(34)$ \\
Microadenoma, $n(\%)$ & $4(29)$ \\
Macroadenoma, $n(\%)$ & $10(71)$ \\
IGF1, ng/mL; IGF1 (x ULN) & \\
At diagnosis & $848(546-1105) ; 2.9(1.9-3.7)$ \\
Three months after NS & $249(194.5-424) ; 0.9(0.7-1.5)$ \\
One year after NS & $226(162-364) ; 0.7(0.6-1.2)$ \\
Random GH, ng/mL & \\
Postoperative day one & $1.4(0.9-2.4)$ \\
Postoperative day two & $0.9(0.3-1.7)$ \\
Three months after NS & $1.0(0.4-3.8)$ \\
Nadir GH after OGTT, ng/mL & \\
Three months after NS & $0.3(0.1-0.8)$ \\
\hline
\end{tabular}

Data are presented as the mean $\pm \mathrm{SD}$ or the median (interquartile range)

macroadenomas, but in comparison with microadenomas, the higher percentage was not statistically significant.

On postoperative day one (D1), the median $\mathrm{rGH}$ (D1-rGH) was $1.4 \mathrm{ng} / \mathrm{mL}(0.9-2.4 ; n=41)$ and on postoperative day two (D2), the median rGH (D2-rGH) was $0.9 \mathrm{ng} / \mathrm{mL}(0.3-1.7 ; n=30)$. After 3 months, the median IGF1 was $249 \mathrm{ng} / \mathrm{mL}(194.5-424 ; n=40)$ and the median IGF1 (x ULN) was $0.9(0.7-1.5) ; 65 \%$ of the values were within the reference range. The median $\mathrm{rGH}$ was $1.0 \mathrm{ng} /$ $\mathrm{mL}(0.4-3.8 ; n=38)$ and the median $\mathrm{nGH}$ was $0.3 \mathrm{ng} / \mathrm{mL}$ $(0.1-0.8 ; n=36) ; 77.8 \%$ of subjects achieved an adequate inhibition of GH after the OGTT. After 1 year, the median IGF1 was $226 \mathrm{ng} / \mathrm{mL}(162-364 ; n=41)$, and the median IGF1 (x ULN) was $0.7(0.6-1.2)$. The overall remission rate was $55 \%$, with no difference between macro- and microadenomas ( $57 \%$ vs. $50 \%$; NS).

Using the ROC curves to predict long-term disease persistence, both sensitivity (SE) and specificity (SP) were optimized for D1-rGH at a cut-off value of $2.1 \mathrm{ng} / \mathrm{mL}$, yielding $55.6 \% \mathrm{SE}, 90.9 \% \mathrm{SP}$, a positive likelihood ratio (LH) of 6.11, a negative LH of 0.49 , and an area under the curve (AUC) of $0.783 \pm 0.075$. Three months after NS, among the subjects with a D1-rGH $\leq 2.1 \mathrm{ng} / \mathrm{mL}, 82.7 \%$ showed IGF1 normalization, as well as GH inhibition after

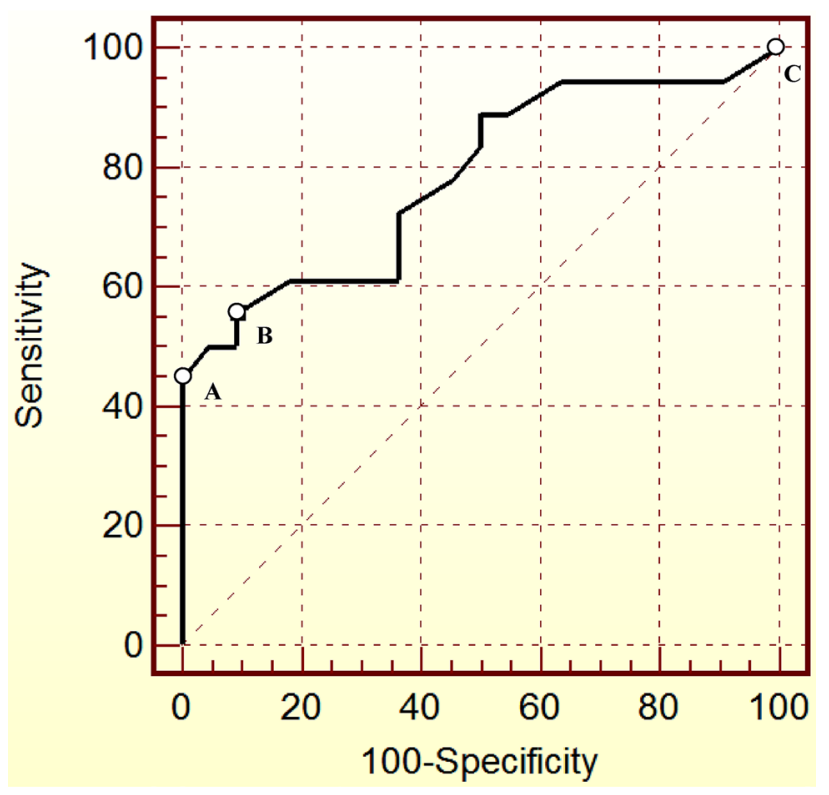

Fig. 1 ROC curves showing different cut-off values for random GH on postoperative day one (D1-rGH) for the early prediction of acromegaly persistence 1 year after neurosurgery. a Cut-off: $2.5 \mathrm{ng} / \mathrm{mL}$; 44.4\% SE; 100\% SP; AUC 0.783. b Cut-off: $2.1 \mathrm{ng} / \mathrm{mL}, 55.6 \%$ SE; 90.9\% SP; AUC 0.783. c Cut-off: $0.3 \mathrm{ng} / \mathrm{mL} ; 100 \%$ SE; 0\% SP; AUC 0.783. SE Sensitivity, SP Specificity

the OGTT. Among those with a D1-rGH $>2.1 \mathrm{ng} / \mathrm{mL}$, $16.6 \%$ achieved IGF1 normalization and $33.3 \%$ reached GH inhibition after the OGTT. The one-year remission rate was $69 \%$ among subjects with a D1-rGH $\leq 2.1 \mathrm{ng} / \mathrm{mL}$ and $16.6 \%$ among those with a D1-rGH $>2.1 \mathrm{ng} / \mathrm{mL}$.

After maximizing specificity for acromegaly persistence, the ROC analysis identified a cut-off value of $2.5 \mathrm{ng} /$ $\mathrm{mL}(100 \% \mathrm{SP} ; 44.4 \% \mathrm{SE})$. A D1-rGH $>2.5 \mathrm{ng} / \mathrm{mL}$ was observed in eight of the 41 subjects $(19.5 \%)$, among which $75 \%$ were women, $62 \%$ had originally been affected by macroadenomas, and $25 \%$ did not have a visible residual tumor. Three months after NS, $78.8 \%$ of the subjects with a $\mathrm{D} 1-\mathrm{rGH} \leq 2.5 \mathrm{ng} / \mathrm{mL}$ showed IGF1 normalization and $84.8 \%$ showed GH inhibition after the OGTT. On the contrary, no patients with a D1-rGH $>2.5 \mathrm{ng} / \mathrm{mL}$ achieved IGF1 normalization or GH inhibition after the OGTT. One year after NS, $67 \%$ of subjects with a $\mathrm{D} 1-\mathrm{rGH} \leq 2.5 \mathrm{ng} / \mathrm{mL}$ achieved remission as compared with $0 \%$ of those with a D1-rGH $>2.5 \mathrm{ng} /$ $\mathrm{mL}$. The proposed cut-off for the detection of acromegaly persistence after 1 year yielded a $44.4 \%$ SE, a $100 \%$ SP, a $100 \%$ positive predictive value, a $69 \%$ negative predictive value, and a $75 \%$ accuracy.

After maximizing the sensitivity for disease remission, the ROC curves provided a cut-off value of $0.3 \mathrm{ng} / \mathrm{mL}$ (100\% SE; 0\% SP). In our population, only three of the 41 subjects $(7 \%)$ had a D1-rGH of $0.3 \mathrm{ng} / \mathrm{mL}$, and none had a $\mathrm{D} 1-\mathrm{rGH}<0.3 \mathrm{ng} / \mathrm{mL}$; thus, further statistical analysis was 
not permitted. The ROC curves displaying different cut-off points for D1-rGH are shown in Fig. 1.

Similarly, both the SE and SP were optimized for D2-rGH at a cut-off value of $0.6 \mathrm{ng} / \mathrm{mL}$, yielding an $\mathrm{SE}$ of $81.8 \%$, an SP of 50\%, a positive LH of 1.64, a negative LH of 0.36 , and an AUC of $0.614 \pm 0.111$. After maximizing the specificity for acromegaly persistence, a cut-off point of $2.9 \mathrm{ng} / \mathrm{mL}$ was identified (100\% SP; $18.2 \%$ SE), but a D2-rGH $>2.9 \mathrm{ng} / \mathrm{mL}$ was only observed in two of 30 subjects $(6.6 \%)$. A cut-off point of $0.1 \mathrm{ng} / \mathrm{mL}$ yielded a $100 \% \mathrm{SE}$ and a $22.2 \% \mathrm{SP}$, but only four of 30 subjects (13.3\%) had a D2-rGH of $0.1 \mathrm{ng} /$ $\mathrm{mL}$, and none had a D2-rGH $<0.1 \mathrm{ng} / \mathrm{mL}$. The ROC curves displaying different cut-off points for D2-rGH are shown in Fig. 2.

\section{Discussion}

This observational study on 41 acromegalic patients suggests that serum random GH on a postoperative day one could be a valid and affordable test for the early prediction of long-term acromegaly persistence. In particular, postoperative day one random $\mathrm{GH}$ values $>2.5 \mathrm{ng} / \mathrm{mL}$ show a positive predictive value of $100 \%$ for disease persistence. On the contrary, serum random GH on postoperative day two does not appear to be a useful predictive factor for either remission or persistence of disease, at least in the present study.

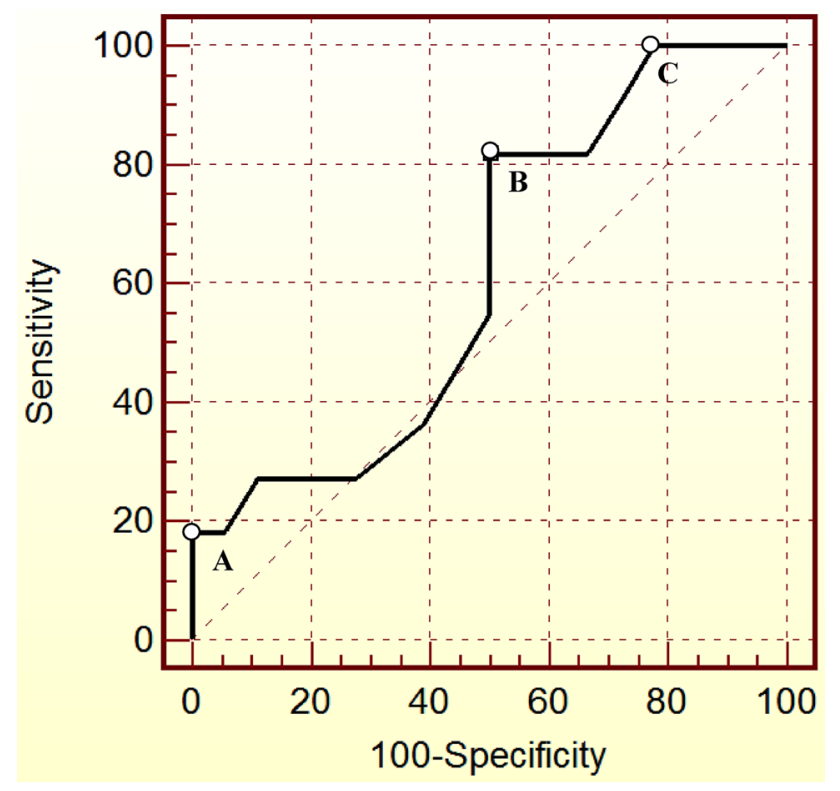

Fig. 2 ROC curves showing different cut-off values for random GH on postoperative day two (D2-rGH) for the early prediction of acromegaly persistence 1 year after neurosurgery. a Cut-off: $2.9 \mathrm{ng} / \mathrm{mL}$; SE 18.2\%; SP 100\%; AUC 0.614. b Cut-off: $0.6 \mathrm{ng} / \mathrm{mL}$; SE $81.8 \%$; SP 50\%; AUC 0.614. c Cut-off: $0.1 \mathrm{ng} / \mathrm{mL}$; SE $100 \%$; SP $22.2 \%$; AUC 0.614. SE Sensitivity, SP Specificity
Our population shares the same characteristics as those described in the literature: acromegaly diagnosis in the 5th decade of life, a similar incidence rate between men and women, and macroadenomas in more than $2 / 3$ of cases [12]. Moreover, the remission rate one year after surgery was $55 \%$ in our sample, which is similar to that reported in previous studies [12]. However, we did not find a difference in remission rate between micro- and macroadenomas, likely due to the relatively small cohort of patients, as well as the adenoma localization, which has not been considered.

The AACE acromegaly guidelines have suggested the early prediction of disease activity, recommending the use of postoperative fasting $\mathrm{GH}$ [6]; however, the recommendation $\mathrm{n} .47$ of the guidelines only has "best evidence" level 2 (evidence obtained from limited outcome data) and Grade $\mathrm{C}$ (action based on weak evidence). Based on a single study [7], the AACE guidelines identified a postoperative day one GH cut-off point of $2 \mathrm{ng} / \mathrm{mL}$ for remission; $99 \%$ of patients with a postoperative $\mathrm{GH}<2 \mathrm{ng} / \mathrm{mL}$ had clinical evidence of disease remission five years after NS. On the contrary, early prediction of disease activity and early postoperative $\mathrm{GH}$ assessment are not even mentioned in the clinical practice guideline of the Endocrine Society [2].

Different studies have attempted to identify early predictors of disease activity, focusing on long-term remission. Intraoperative GH determination was initially proposed, indicating that a reduction in GH levels during the surgical procedure may improve surgical outcomes [13]; however, intraoperative testing is an elaborate and expensive procedure and therefore is not routinely performed [13-15].

The mean of multiple GH measurements between 1 and 3 weeks after NS appeared to be a promising high-sensitivity test for the prediction of a successful long-term surgical outcome; in fact, a mean $\mathrm{GH}$ value $<3 \mathrm{ng} / \mathrm{mL}$ predicted disease remission in $100 \%$ of cases [16]. These interesting results, however, required multiple clinic admissions, whereas a single early GH evaluation can be easily performed during the patient's hospitalization.

Some studies have attempted to analyze the use of an early nadir GH after an OGTT. Although OGTT results become more accurate three months after NS [17], many authors have concluded that an early OGTT has a good positive predictive value for acromegaly remission $[18,19]$. For example, an OGTT in the first week after NS yielded an 81.7\% SE and a 95.1\% SP in diagnosing long-term remission [7]. Sarkar et al. evaluated both random GH on postoperative day one and nadir GH after an OGTT on day seven; the optimal cut-off for random GH was $3.66 \mathrm{ng} / \mathrm{mL}$ (93.1\% SE; $79.2 \% \mathrm{SP})$ and for nadir $\mathrm{GH}$ was $2.55 \mathrm{ng} / \mathrm{mL}(93.1 \% \mathrm{SE}$; $77.4 \%$ SP) [20]. Similar to the mean of multiple measurements, an OGTT on day seven could also lead to time- and cost-consuming hospital readmission. Moreover, OGTT cannot be performed in subjects with diabetes. 
Postoperative day one random $\mathrm{GH}$ values $<2 \mathrm{ng} / \mathrm{ml}$ were highly predictive of long-term remission of acromegaly in a large retrospective study [21]. Other studies have analyzed the diagnostic performance of early random $\mathrm{GH}$ with different cut-off points and days of collection. Kim et al. measured random GH on the first three postoperative days after NS and found that day one was the best predictor of acromegaly remission [7]. Dutta et al. assessed random GH six hours post-NS and on days one to five after surgery; GH values $\leq 1.5 \mathrm{ng} / \mathrm{mL}$ at six hours showed the highest specificity $(83.3 \%)$ and $\leq 1.03 \mathrm{ng} / \mathrm{mL}$ on day one showed the best sensitivity (90.5\%) [22]. The authors also found that the diagnostic performance of other time points was lower, with day four being the worst. Similarly, in our study, random GH on day one appeared to be a better predictor of disease status than that on day two.

Contrarily, Antunes et al. found that GH levels $<1.57 \mathrm{mcg} / \mathrm{L}$ on day two yielded a $93 \% \mathrm{SE}$ and an $86 \%$ SP in diagnosing short-term IGF1 normalization. However, this study including 69 patients do not provide data on longterm remission [23].

We note that many diagnostic tests described in the literature are not highly specific for acromegaly remission, since normal post-surgery GH levels could also be due to low disease activity. Therefore, switching our perspective, we used the ROC curves to detect patients with a higher probability of acromegaly persistence.

The optimal sensitivity/specificity cut-off value for the day one random GH yielded a low sensitivity and a high specificity for disease persistence. After maximizing specificity, we identified a cut-off point with a positive predictive value of $100 \%$ but with the limitation of a small sample above the cut-off.

The clinical implications of these results are relevant since we were able to identify patients with a very high risk of disease persistence, who most likely would not benefit from intermediate hormonal assessments, i.e., 3 months after pituitary surgery. Based on the limited results of our study, we cannot recommend any disease management alternative to the international guidelines, but we hypothesize that in the future, an early confirmation of disease activity may guide endocrinologists through clinical algorithms including early reintervention or medical therapy without delay.

The main limitation of our study is the relatively small sample size. However, larger studies had a retrospective approach; moreover, when compared with prospective studies, we consecutively recruited in a shorter time and in a single-center, focusing on long-term outcomes too. So, our results need to be confirmed in a larger cohort of patients; in particular, their reproducibility should be evaluated in other neurosurgical centers similar to ours, where a neurosurgeon with expertise in the surgical management of pituitary adenomas is available, as seen in the Italian survey on pituitary surgery [24]. It should be noted that the lack of uniformity of GH and IGF1 assays across different centers could lead to heterogeneous and non-reproducible data. As soon as a large sample size will be prospectively achieved, it would be interesting to employ a machine learning (ML) algorithm to early predict disease persistence, based not only on D1-rGH but also on several variables. To date, few ML-based models have been proposed for predicting off-medication remission with high performance. AUC of the best full model was 0.888 in a training, retrospective cohort of 833 patients ( 0.871 in the external cohort) [25]; similarly, AUC of the best full model was 0.855 in a training, retrospective cohort of 534 patients ( 0.817 in the validation cohort) [26].

Interestingly, in comparison with day one, day two random GH had lower diagnostic performance, similar to observations of previous studies. In our case, the main reason was the limited statistical power; however, certain unknown biological mechanisms may be involved, since a time-dependent decrease in diagnostic performance has been observed. A lack of tumor-induced suppression of normal GH secretion and the effects of local factors such as ischemia, fibrosis, cytokines, and inflammation could all play a role in this interesting phenomenon and justify a "sooner the better" approach to postoperative GH scheduling.

In conclusion, we show that random $\mathrm{GH}$ on a postoperative day one is a highly specific test for the early prediction of acromegaly persistence one year after pituitary surgery. After maximizing specificity, our test yields a positive predictive value of $100 \%$, and thus predicts long-term disease persistence with a great degree of certainty. On the contrary, the diagnostic performance of random GH on postoperative day two does not demonstrate clinical utility.

We suggest an evaluation of these preliminary data in a broader validation sample, extending the protocol to other pituitary units. It is unclear whether patients with a postoperative day one random $\mathrm{GH}>2.5 \mathrm{ng} / \mathrm{mL}$ may benefit from an intermediate reassessment of disease status; however, the cut-off value must be validated prior to modifying the postoperative management of acromegaly. Until then, clinicians should follow the recommendations and timings suggested by the international guidelines.

Funding Open access funding provided by Università degli Studi di Torino within the CRUI-CARE Agreement.. None.

\section{Declarations}

Conflict of interest The authors declare that they have no conflict of interest. 
Ethics approval The study was approved by the local Ethical Committee.

Consent to participate Informed consent was obtained from all participants included in the study.

Research involving human participants and/or animals The study was performed in accordance with the ethical standards as laid down in the 1964 Declaration of Helsinki and its later amendments or comparable ethical standards.

Open Access This article is licensed under a Creative Commons Attribution 4.0 International License, which permits use, sharing, adaptation, distribution and reproduction in any medium or format, as long as you give appropriate credit to the original author(s) and the source, provide a link to the Creative Commons licence, and indicate if changes were made. The images or other third party material in this article are included in the article's Creative Commons licence, unless indicated otherwise in a credit line to the material. If material is not included in the article's Creative Commons licence and your intended use is not permitted by statutory regulation or exceeds the permitted use, you will need to obtain permission directly from the copyright holder. To view a copy of this licence, visit http://creativecommons.org/licenses/by/4.0/.

\section{References}

1. Valdemarsson S, Ljunggren S, Bramnert M, Norrhamn O, Nordström CH (2000) Early postoperative growth hormone levels: high predictive value for long-term outcome after surgery for acromegaly. J Intern Med 247(6):640-650. https://doi.org/10.1046/j. 1365-2796.2000.00667.x

2. Katznelson L, Laws ER, Melmed S, Molitch ME, Murad MH, Utz A et al (2014) Acromegaly: an endocrine society clinical practice guideline. J Clin Endocrinol Metab 99(11):3933-3951. https:// doi.org/10.1210/jc.2014-2700

3. Jane JA, Starke RM, Elzoghby MA, Reames DL, Payne SC, Thorner MO et al (2011) Endoscopic transsphenoidal surgery for acromegaly: remission using modern criteria, complications, and predictors of outcome. J Clin Endocrinol Metab 96(9):2732-2740. https://doi.org/10.1210/jc.2011-0554

4. Starke RM, Raper DM, Payne SC, Vance ML, Oldfield EH, Jane JA (2013) Endoscopic vs microsurgical transsphenoidal surgery for acromegaly: outcomes in a concurrent series of patients using modern criteria for remission. J Clin Endocrinol Metab 98(8):3190-3198. https://doi.org/10.1210/jc.2013-1036

5. Giustina A, Chanson P, Bronstein MD, Klibanski A, Lamberts S, Casanueva FF et al (2010) A consensus on criteria for cure of acromegaly. J Clin Endocrinol Metab 95(7):3141-3148. https:// doi.org/10.1210/jc.2009-2670

6. Katznelson L, Atkinson JL, Cook DM, Ezzat SZ, Hamrahian AH, Miller KK et al (2011) American association of clinical endocrinologists medical guidelines for clinical practice for the diagnosis and treatment of acromegaly-2011 update. Endocr Pract 17(Suppl 4):1-44. https://doi.org/10.4158/ep.17.s4.1

7. Kim EH, Oh MC, Lee EJ, Kim SH. Predicting long-term remission by measuring immediate postoperative growth hormone levels and oral glucose tolerance test in acromegaly. Neurosurgery. 2012;70(5):1106-13; discussion 13. doi: https://doi.org/10.1227/ NEU.0b013e31823f5c16

8. Nishioka H, Fukuhara N, Yamaguchi-Okada M, Takeshita A, Takeuchi Y, Yamada S (2017) Pitfalls in early biochemical evaluation after transsphenoidal surgery in patients with acromegaly.
Endocr J 64(11):1073-1078. https://doi.org/10.1507/endocrj. EJ17-0261

9. Rotermund R, Burkhardt T, Rohani Z, Jung R, Aberle J, Flitsch J (2018) Value of early postoperative random growth hormone levels and nadir growth hormone levels after oral glucose tolerance testing in acromegaly. Growth Horm IGF Res 41:64-70. https:// doi.org/10.1016/j.ghir.2018.03.002

10. Penner F, Prencipe N, Pennacchietti V, Pacca P, Cambria V, Garbossa $\mathrm{D}$ et al (2019) Super giant growth hormone-secreting pituitary adenoma in young woman: from ventricles to nose. World Neurosurg 122:544-548. https://doi.org/10.1016/j.wneu.2018.11. 069

11. Aimaretti G, Boschetti M, Corneli G, Gasco V, Valle D, Borsotti $M$ et al (2008) Normal age-dependent values of serum insulin growth factor-I: results from a healthy Italian population. J Endocrinol Invest 31(5):445-449. https://doi.org/10.1007/BF03346389

12. Lavrentaki A, Paluzzi A, Wass JA, Karavitaki N (2017) Epidemiology of acromegaly: review of population studies. Pituitary 20(1):4-9. https://doi.org/10.1007/s11102-016-0754-x

13. Lüdecke DK (1985) Recent developments in the treatment of acromegaly. Neurosurg Rev 8(3-4):167-173. https://doi.org/10.1007/ bf01815441

14. Ludecke DK, Abe T (2006) Transsphenoidal microsurgery for newly diagnosed acromegaly: a personal view after more than 1000 operations. Neuroendocrinology 83(3-4):230-239. https:// doi.org/10.1159/000095533

15. Kurosaki M, Luedecke DK, Abe T (2003) Effectiveness of secondary transnasal surgery in $\mathrm{GH}$-secreting pituitary macroadenomas. Endocr J 50(5):635-642. https://doi.org/10.1507/endocrj.50.635

16. Yamada S, Aiba T, Takada K, Ozawa Y, Shimizu T, Sawano S et al (1996) Retrospective analysis of long-term surgical results in acromegaly: preoperative and postoperative factors predicting outcome. Clin Endocrinol (Oxf) 45(3):291-298. https://doi.org/ 10.1046/j.1365-2265.1996.8080817.x

17. Kristof RA, Neuloh G, Redel L, Klingmüller D, Schramm J (2002) Reliability of the oral glucose tolerance test in the early postoperative assessment of acromegaly remission. J Neurosurg 97(6):1282-1286. https://doi.org/10.3171/jns.2002.97.6.1282

18. Feelders RA, Bidlingmaier M, Strasburger CJ, Janssen JA, Uitterlinden P, Hofland LJ et al (2005) Postoperative evaluation of patients with acromegaly: clinical significance and timing of oral glucose tolerance testing and measurement of (free) insulin-like growth factor I, acid-labile subunit, and growth hormone-binding protein levels. J Clin Endocrinol Metab 90(12):6480-6489. https://doi.org/10.1210/jc.2005-0901

19. Takahashi JA, Shimatsu A, Nakao K, Hashimoto N (2004) Early postoperative indicators of late outcome in acromegalic patients. Clin Endocrinol (Oxf) 60(3):366-374. https://doi.org/10.1046/j. 1365-2265.2003.01900.x

20. Sarkar S, Jacob KS, Pratheesh R, Chacko AG. Transsphenoidal surgery for acromegaly: predicting remission with early postoperative growth hormone assays. Acta Neurochir (Wien). 2014;156(7):1379-87; discussion 87. doi: https://doi.org/10.1007/ s00701-014-2098-5

21. Krieger MD, Couldwell WT, Weiss MH (2003) Assessment of long-term remission of acromegaly following surgery. J Neurosurg 98(4):719-724. https://doi.org/10.3171/jns.2003.98.4.0719

22. Dutta P, Korbonits M, Sachdeva N, Gupta P, Srinivasan A, Devgun JS et al (2016) Can immediate postoperative random growth hormone levels predict long-term cure in patients with acromegaly? Neurol India 64(2):252-258. https://doi.org/10.4103/00283886.177622

23. Antunes X, Ventura N, Camilo GB, Wildemberg LE, Guasti A, Pereira PJM et al (2018) Predictors of surgical outcome and early criteria of remission in acromegaly. Endocrine 60(3):415-422. https://doi.org/10.1007/s12020-018-1590-8 
24. Solari D, Zenga F, Angileri FF, Barbanera A, Berlucchi S, Bernucci C et al (2019) A survey on pituitary surgery in Italy. World Neurosurg 123:e440-e449. https://doi.org/10.1016/j.wneu.2018. 11.186

25. Qiao N, Shen M, He W, He M, Zhang Z, Ye H et al (2021) Machine learning in predicting early remission in patients after surgical treatment of acromegaly: a multicenter study. Pituitary 24(1):53-61. https://doi.org/10.1007/s11102-020-01086-4

26. Fan Y, Li Y, Feng S, Bao X, Feng M, Wang R (2020) Development and assessment of machine learning algorithms for predicting remission after transsphenoidal surgery among patients with acromegaly. Endocrine 67(2):412-422. https://doi.org/10. 1007/s12020-019-02121-6

Publisher's Note Springer Nature remains neutral with regard to jurisdictional claims in published maps and institutional affiliations. 